\title{
Splošna leksika in večpodročni termini $v$ govoru turizma
}

\author{
VESNA MiKOLIČ \\ Univerza na Primorskem, Fakulteta za humanistične študije, Znanstveno-raziskovalno \\ središče, Garibaldijeva 1, SI-6000 Koper,vesna.mikolic@fhs.upr.si
}

SCN VIII/1 [2015], 188-202

\begin{abstract}
V prispevku na primeru Turističnega terminološkega slovarja TURS predstavljamo specifike turistične leksike, ki se kažejo kot zelo intenzivni terminologizacijski in determinologizacijski procesi oz. sovplivanje splošne leksike in terminologije različnih strok v okviru turističnega področja. V slovarskem sestavku v TURS se področje, $s$ katerega prihaja termin, kaže v oznaki za vrsto turizma in področni oznaki, definiciji in ponazarjalnem gradivu. Definiranje turističnega (pod)področja se kaže kot posebej pomembno pri večpodročnih terminih, kjer se pomeni oziroma njihove pojmovne vsebine na različnih področjih različno prepletajo.
\end{abstract}

Drawing upon the Dictionary of Tourism Terminology (TURS) the study shows the specific traits of tourism lexis, which is characterized by strong terminologization and de-terminologization processes, or rather, by the interaction of the general lexicon and multidisciplinary terminology within the field of tourism. Lexical entries in the dictionary provide information about the source field of a term by indicating the type of tourism and a specific field indication, the definition of term, and illustrative examples. Determining the tourism subfields is especially important with multidisciplinary terms, since their meanings and concepts intertwine differently in various fields.

Ključne besede: turizem, terminologija, terminologizacija, večpomenskost, večpodročnost, transdisciplinarnost

Key words: tourism, terminology, terminologization, polysemy, multidisciplinarity, transdisciplinarity

\section{Sovplivanje splošnega in področnih jezikov v turističnem govoru}

Namen prispevka je predstaviti specifike turistične leksike, ki se kažejo kot zelo intenzivni terminologizacijski in determinologizacijski procesi oz. sovplivanje 
splošne leksike in terminologije različnih strok v okviru turističnega področja. $\mathrm{Ob}$ tem posebej izpostavljamo večpodročnost in večpomenskost, ki sta zaradi omenjenih jezikovnih procesov v turistični terminologiji pogost pojav. ${ }^{1}$

Turizem je pomembno in hitro razvijajoče se družbeno področje, ki ga sestavljajo dejavnosti različnih strok in družbenih resorjev. Prav tako so turistične študije meddisciplinarna in mlada znanstvena veda, ki je šele $\mathrm{v}$ fazi oblikovanja. Večpodročnost turizma namreč le-tega sili k interdisciplinarnemu raziskovalnemu pristopu, toda zaradi večdisciplinarne narave turističnih študij dogovora o skupni definiciji le-teh še ni. Zaradi pluralizma vidikov najbrž res ne moremo govoriti o enoviti turistični vedi, se pa turistični študiji kažejo kot metaznanost, ki lahko konceptualna in metodološka vprašanja na področju turizma preseže prav s svojim transdiciplinarnim poslanstvom, ki zahteva koordiniranje, usklajevanje in tesno povezovanje različnih znanstvenih ved in teorij (Wöhler v Lebe idr. 2012: 657).

Večdisciplinarna narava turizma in turistične vede ter odprta vprašanja glede samostojnosti slednje se seveda odražajo tudi v turistični terminologiji. Vprašanje je, ali lahko (že) govorimo o turističnem jeziku ali jeziku turizma. Vzporedno z zavedanjem o večpodročnosti turizma samega in s povečevanjem interesa različnih znanstvenih ved za obravnavo turizma se $\mathrm{v}$ jezik turizma vse bolj vključuje strokovno izrazje vseh teh strokovnih področij in znanstvenih disciplin oziroma raste zavest, da so termini teh strok in ved tudi termini turistične stroke in vede. Hkrati pa v turizem vstopa širok krog uporabnikov; kot turisti smo vsi, vsaj občasno, del turistične diskurzivne skupnosti, ki je zato zelo široka in mobilna, zato so tudi procesi terminologizacije splošne leksike in determinologizacije terminov različnih strok zelo dinamični.

Rita Temmerman, ki je razvila sociokognitivni pristop k terminologiji, podobno ugotavlja, da termini ne ostajajo zaprti v okvir ene stroke, pač pa da se nasprotno gibljejo v številnih, največkrat sorodnih disciplinah, ki se deloma prekrivajo $\mathrm{v}$ vsebini. Tako pogosto nastajajo in se uporabljajo na večdisciplinarnih področjih in pomenijo orodje za različne vrste uporabnikov. Posledica tega je tudi dejstvo, da je enoznačnost terminov pogosto nerealna zahteva; nasprotno sopomenskost odraža natančnost $\mathrm{v}$ perspektivi sporočevalca, večpomenskost pa se kaže funkcionalna kot izraz vedno globljega poznavanja in razumevanja snovi (Temmerman 2000: 132).

To vse smo želeli upoštevati tudi v Turističnem terminološkem slovarju TURS, ${ }^{2}$ ki je zasnovan na temelju sodobnega koncepta turizma kot trans-

1 Širše smo jezikovne procese na področju turistične terminologije opisali v elaboratu Turistični terminološki slovar - predstavitev izhodišč in učinkov projekta ter opis slovarja TURS kot glavnega rezultata projekta (Mikolič 2013a), od koder sedaj povzemamo ugotovitve, povezane s pojavoma večpodročnosti in večpomenskosti.

2 Turistični terminološki slovar TURS je bil oblikovan v okviru aplikativnega raziskovalnega projekta Turistični terminološki slovar pri Znanstveno-raziskovalnem središču Univerze na Primorskem (financer: ARRS, projektni partner: STO, nosilka: dr. Vesna Mikolič, 2008-2011). Do sedaj ima TURS pribl. 1000 gesel z angleškimi vzporednicami in je prosto dostopen na spletnem portalu Termania http://www.termania.net/slovarji/78/ 
disciplinarne dejavnosti in kot rastoča slovarska zbirka slovenske turistične terminologije. Takšno zasnovo mu omogočata povezava s korpusom avtentičnih, področno in zvrstno raznolikih turističnih besedil korpusa TURK in spletna postavitev na portalu Termania, ki spodbuja vključevanje najširšega kroga strokovnjakov, izvajalcev in uporabnikov turističnih storitev v proces nadaljnjega razvijanja turistične terminologije. S tem ko se upošteva celoten turistični diskurz, $\mathrm{tj}$. govor celotne turistične govorne skupnosti, $\mathrm{v}$ okviru katerega se prepletajo splošni jezik in različni strokovni jeziki, se lahko razvijajo tudi turistični študiji kot mlada znanstvena disciplina. Hkrati pa je na ta način slovarska zbirka tudi odraz slovenskega turizma, saj s korpusno metodo in luščenjem terminov lahko ugotovimo, katera področja, $s$ katerih prihajajo najpogostejši termini, so za slovenski turizem najbolj relevantna.

\section{Pomen sobesedila pri oblikovanju turistične terminologije}

Upoštevajoč omenjene značilnosti turistične terminologije ima pri njenem oblikovanju oziroma prepoznavanju terminov in razumevanju njihovega pomena posebno vlogo sobesedilo. Čeprav načeloma terminografija izhaja iz pojmovnega sistema stroke, v katerem so pojmi medsebojno povezani, zaradi česar naj bi bil njihov pomen manj odvisen od sobesedila (Žagar Karer 2011: 46), pa je danes, predvsem pri hitro razvijajočih se strokah, pri oblikovanju kriterijev terminološkosti merodajna predvsem ustrezna opredelitev sporazumevalnega okolja, v katerem se termin lahko pojavi (Pearson, v Logar, Vintar 2008: 9-10). To pa je najlaže razvidno iz področnih ali specializiranih korpusov. Pri tem se je potrebno zavedati, da so »korpusi strokovnih besedil razrahljali več mej: mejo med terminološko in neterminološko leksiko, mejo, do katere še govorimo o večbesedni poimenovalni enoti in čez katero je že prostor kolokacij, ter mejo, ki določa, ali gre za termin področja, ki ga obravnavamo, ali ne« (Logar, Vintar 2008: 14). ${ }^{3}$

turisticni-terminoloski-slovar in http://www.amebis.si/aspplus. Korpus turističnih besedil TURK je bil oblikovan v okviru temeljnega raziskovalnega projekta »Večjezični korpus turističnih besedil - informacijski vir in analitična baza slovenske naravne in kulturne dediščine« istega izvajalca, financerja in iste nosilke v letih 2006-2008. Gre za zbirko turističnih besedil v slovenskem, italijanskem in angleškem jeziku s 30.000 .000 besedami, prosto dostopen na http://turk.upr.si/.

${ }^{3}$ Avtorici Logar in Vintar (2008, 9-10) na istem mestu še natančneje opišeta pomen analize sobesedila in s tem tudi korpusnega pristopa za prepoznavanje terminov, še posebej v strokah, ki jih manj ljudi dojema kot ozko specializirane, kar seveda velja tudi za turistično stroko: »Zadrego, v kateri smo se znašli pri samostalnikih, že prej pa tudi pri glagolih, opisuje že Pearson (1998: 26-28). Avtorica meni, da ostaja soodvisnost med številom ljudi, ki poznajo leksiko določenega specializiranega področja, in percepcijo te leksike kot specializirane: manj, kot je takih ljudi, bolj je verjetno, da bo taka leksika (in področje) dojeta kot specializirana. Kar torej ljudi po občutku usmerja v odgovor na vprašanje, ali je nek leksem termin ali ne, je njegova relativna nepogostost v splošnem 
Večina področnih korpusov namreč ne odraža le strokovnega jezika, pač pa tudi celoten diskurz nekega področja, v okviru katerega se strokovni izrazi srečujejo s splošno leksiko in strokovni izrazi enega področja s strokovnimi izrazi drugega področja. To velja tudi za turistični korpus TURK (2009), ki zajema različne vrste besedil, od znanstvenih in strokovnih do pravnih, poslovnih, oglaševalskih in publicističnih. Turizem je namreč strokovno področje, ki posega na različna področja družbenega življenja, poleg tega pa vanj vstopa širok krog uporabnikov, kot turisti smo vsi, vsaj občasno, del turistične diskurzivne skupnosti, ki je zato zelo široka in mobilna. Hkrati pa se turistična znanost šele oblikuje in je tudi zato potrebno zajeti vsa družbena področja in vse ravni družbenega življenja, če želimo uzreti turistični diskurz oziroma področni govor in s tem (nacionalni) turizem v vsej svoji celovitosti.

Nasploh se cilji terminologije in terminografije v zadnjem času od preskriptivnosti in standardizacije preusmerjajo $\mathrm{k}$ deskriptivnosti in s tem se bistveno spreminjajo tudi terminološke in terminografske metode. Besedilni korpusi, ki se že rutinsko uporabljajo v leksikografiji, postajajo imperativ tudi za terminografijo (gl. Alcina 2011; Temmerman 2000; Wright, Budin 2001). Področni korpusi kot elektronske zbirke besedil nekega področja so tako zelo dragoceno orodje, če želimo za potrebe terminološkega slovarja priti do opisa dejanske jezikovne rabe na nekem družbenem področju in s tem obenem v slovarju izraziti tudi kulturo naroda in specifike nacionalne stroke. Slednje je za turizem kot stroko, ki ima že v svoji osnovni naravi težnjo po specifiki, drugačnosti, še toliko bolj pomembno.

Prav tako je korpusni pristop še posebej koristen, če lahko korpus neposredno povežemo s slovarjem v elektronski obliki (npr. tako, da so primeri rabe v slovarskem sestavku vzeti neposredno iz korpusa in lahko hkrati pregledujemo slovar in korpus, kot je to v primeru TURK-a in TURS-a). Korpus in e-terminološki slovar pa sta zaradi možnosti nadgrajevanja lahko dobra osnova za oblikovanje še drugih jezikovnih priročnikov na področju terminologije, kot sta leksikon in enciklopedija.

Prihodnost terminoloških slovarjev Žagar Karer vidi prav v elektronskem mediju, še posebej v spletu, saj se zaradi boljše in hitre dostopnosti takšnih slovarjev večajo možnosti, da pri nastajanju in urejanju terminologije sodeluje širši krog uporabnikov, ki sicer niso avtorji slovarja. Takih terminoloških slovarjev, ki so postavljeni na splet in vabijo uporabnike k sodelovanju pri

jeziku (in torej nerazumljivost pomena) in/ali sporazumevalno okolje, v katerem je rabljen. Pearson tudi ugotavlja, da pogostost v splošnem jeziku ne more biti merodajna za opredeljevanje, katera beseda je termin in katera ni, da pa je sporazumevalno okolje (vključno s sobesedilom), v katerem se pojavlja, pri odgovoru na to vprašanje vsekakor treba upoštevati - še več, avtorica verjame, da je ustrezna opredelitev sporazumevalnega okolja, za katerega je verjetno, da se bo v njem pojavil termin, najboljša pot do ločevanja med terminološko in neterminološko leksiko. Iz navedenega tudi v kontekstu pričujoče raziskave izpeljujemo spoznanje, da če je strokovno izrazje lastnost strokovnih jezikov in ga lahko opredelimo le na podlagi sobesedila, je edina sprejemljiva metoda za delo korpusni pristop.« 
nadaljnjem razvijanju terminologije, je danes tudi v Sloveniji že kar nekaj, npr. slovar informatike Islovar (http://www.islovar.org/iskanje_enostavno.asp), slovar terminov v spletnem oglaševanju iPROM (http://www.iprom.si/slovar. html) in nekateri terminološki slovarji na spletnem portalu Termania ${ }^{4}$ (http:// www.termania.net/). Seveda pa mora biti terminološko delo tudi v tem primeru odgovorno in vsaj do neke mere nadzorovano (Žagar Karer 2011: 51). In čeprav je takšen proces dolgotrajnejši - kot ugotavlja tudi Lebetova (2012: VII), sestavljanje originala lahko traja več let, zato se je kdaj potrebno odločiti tudi za hitrejše poti do jezikovnih priročnikov, kot je npr. prevod kakovostnega tujega leksikona - ga je vseeno vredno začeti. Terminološki slovarji so namreč atributi razvitih strok (Humar 2004: 23) in tako je tudi spletni turistični terminološki slovar kot rastoči slovar slovenskega turizma korak naprej k doseganju zrelosti turistične vede in stroke (Mikolič 2013a).

\section{Področja turizma in tipologija turistične terminologije v TURS}

V slovarju TURS se termini trenutno razvrščajo v 43 vrst turizma in na 81 področij, od tega 6 ožjeturističnih (ekonomija, gostinstvo, nastanitvena dejavnost, promet, turistično posredništvo, turistično trženje). Po korpusnem pristopu so se pokazali kot najpogostejši termini s področja kulinarike (75 terminov), športa (74 t.), gostinstva (70 t.), ekonomije (60 t.), medicine (50 t.), umetnosti (43 t.) in prometa (44 t.), kar pomeni, da imajo ta področja v okviru slovenskega turizma (npr. medicina v okviru zdraviliškega in zdravstvenega turizma) nedvomno velik pomen.

Glede na pomen terminološkega kandidata za različna področja turizma lahko termine uvrščamo v 3 skupine: 1.a) splošnoturistični termini, ki se uporabljajo izključno v turizmu in jih ne moremo uvrstiti v nobeno (pod)področje (npr. turistična dejavnost, turistična sezona) ali b) termini z ožjeturističnih področij, to so področja, ki so v večjem delu vključena v turistično dejavnost oz. so zanjo ključna: turistično posredništvo, gostinstvo, promet in ekonomija oz. turistično trženje (npr. turistična ponudba, receptivni trg, kategorizacija, celovit turistični proizvod, hotel), 2. termini drugega strokovnega/družbenega (pod)področja (npr. domača obrt, hiperaktivnost, zmajarstvo, regeneracija, sankališče) in 3. termini iz splošne leksike (npr. dragocenost, nahrbtnik, potica, edinstvenost, obiskovalec), ki se oboji vključujejo v področje turizma in so s turizmom kot sestavljeno dejavnostjo neločljivo povezani (Mikolič 2013: 258; Mikolič 2013a: 17-22).

\footnotetext{
${ }^{4}$ Na spletnem portalu Termania slovenskega podjetja Amebis je poleg TURS objavljeno še več terminoloških slovarjev, kot npr. Bibliotekarski terminološki slovar, Mikrobiološki slovar, Slovar družboslovne informatike, Slovenski medicinski slovar, Računalniški slovarček, Terminološki slovar vzgoje in izobraževanja; od teh so nekateri nastali kot spletna verzija tiskane izdaje, drugi pa so se oblikovali neposredno na spletni aplikaciji, prav tako so nekateri zaključene zbirke, drugi so odprti za dopolnjevanje.
} 
1. vrsta terminov: termini prve kategorije Hoffmanovega modela, tj. splošnoturistični termini (turistična dejavnost, turistična sezona) in tisti z ožjeturističnih področij (turistična ponudba, receptivni trg, kategorizacija)

2. vrsta terminov: termini druge kategorije Hoffmanovega modela - termini z drugih strokovnih področij (domača obrt, hiperaktivnost, zmajarstvo)

3. vrsta terminov: termini prve ali druge kategorije Hoffmanovega modela, obenem tudi del splošne leksike (npr. dragocenost, nahrbtnik, potica)

Tabela 1: Tipologija turistične terminologije (Mikolič 2013: 259; Mikolič 2013a: 19).

V slovarskem sestavku v TURS se področje, s katerega prihaja termin, kaže v oznaki za vrsto turizma in področni oznaki, definiciji in ponazarjalnem gradivu. Termini, ki ne sodijo na nobeno posebno področje, pač pa so splošnoturistični termini, oznake področja nimajo (npr. edinstveni, turistična sezona, dogodivščina).

Predvsem pri terminih druge in tretje skupine je pogosta polisemija z izrazi iz drugih strokovnih jezikov in splošnega jezika, čeprav med pomeni prihaja vsaj do delnih pomenskih premikov. Če ima termin več pomenov, so definicije oštevilčene. $\mathrm{V}$ takih primerih so $\mathrm{s}$ številko v oklepaju oštevilčeni tudi vsi drugi elementi slovarskega sestavka (vrste in področja turizma, primeri rabe, sopomenke, prevodne ustreznice), tako da je razvidna povezava $\mathrm{z}$ ustrezno definicijo. Če so pomeni med seboj povezani, so razvrščeni od širšega k ožjim pomenom, sicer pa od pogostejšega $\mathrm{k}$ manj pogostemu.

Definicije so večinoma pomenskosestavinske, v okviru besednih družin (npr. animacija, animacijski) pa tudi sklicevalne. Definicije so oblikovane v obliki povedi, pri čemer je prvi del večinoma nestavčni, stavčni vzorec pa navadno nastopi v drugem delu po podpičju (krajša pojasnila) ali piki (daljša pojasnila). $\mathrm{V}$ tem delu so podane dodatne informacije, pogosto povezane s pomenskim premikom, ki ga termin določenega področja ali izraz iz splošnega jezika pridobi z rabo na področju turizma. Prav tako so v drugem delu lahko podane dodatne, enciklopedične informacije.

\section{Terminologizacija splošne leksike}

Pogosto se dogaja, da splošna leksika z nadgradnjo splošnega pomena pridobi ožji pomen in postane pojem $\mathrm{v}$ okviru turistične stroke. Tako v primeru pridevnika edinstven kakovostni pridevnik s pomenom »ki zelo izstopa po pomembnosti, vrednosti« (SSKJ, slika 1) v turističnem diskurzu pridobi dodaten, bolj natančen pomen »enkraten, edini take vrste in zato izstopa po pomembnosti, vrednosti« (TURS, slika 2) in določno obliko, s tem postane vrstni pridevnik in tudi turistični termin. Ker gre za splošnoturistični termin, nima oznake področja; prav tako nima oznake vrste turizma, saj se uporablja v okviru številnih vrst turizma. 
edínstven -a -o prid. (î)

1. nav. ekspr. ki zelo izstopa po pomembnosti, vrednosti: to je zate edinstvena prilika; edinstvena skulptura; edinstveno doživetje / sprejem je bil nadvse veličasten, edinstven; edinstvena lepota jezera / on je edinstven človek izreden, čudovit

2. knjiž. edino pravi, edino mogoč: užitek mu pomeni edinstveni smisel življenja

edínstveno prisl.: edinstveno oblikovan obraz; sam.: rad bi doživel nekaj velikega, edinstvenega

Slika 1: Slovarski sestavek za izraz edinstven v Slovarju slovenskega knjižnega jezika (SSKJ).

edinstveni pridevnik

Ki je enkraten, edini take vrste in zato izstopa po pomembnosti, vrednosti.

o edinstveni muzej

- edinstveni naravni pojavi

- Šele zdaj Reka dokončno vstopa $v$ divje podzemlje, $v$ svoj edinstveni podzemeljski

kanjon, ki nima primere.

- Vsi dogodki pa težijo $k$ temu, da so na nek način edinstveni, saj s tem

organizatorji želijo pritegniti čim več obiskovalcev.

- Zahvaljujoč tem izbiram je planinska koča L’Albergh prva planinska koča v

Evropi in, če smo natančni, edinstveni namestitveni objekt v pokrajini Piemont, ki je pridobil prestižno evropsko nagrado EU Marjetica.

GL. edinstvenost

Angleški prevod: unique

Slika 2: Slovarski sestavek za termin edinstveni v Turističnem terminološkem slovarju (TURS).

\section{Polisemija večpodročnih terminov}

\subsection{Pomenski premik pri turističnih terminih z drugih strokovnih področij}

Kot je bilo predstavljeno v drugem poglavju, so številni turistični termini primarno termini drugih strokovnih področij. Ko pojmovna vsebina nekega področja pridobi določeno vlogo v okviru turistične dejavnosti, pride pogosto do pomenskega premika, ki ga zabeležimo in opišemo v drugem delu definicije (v nestavčni obliki največkrat za vejico, v stavčni pa za podpičjem v prvi in edini povedi ali za piko v novi povedi), ali pa je pomen na področju turizma razviden že samo iz kvalifikatorja za vrsto turizma in (pod)področje ter iz ponazarjalnega gradiva.

Tako se definicija termina zdravstvena dejavnost v TURS-u razlikuje od definicije istega termina v Slovenskem medicinskem slovarju v drugem delu, kjer je zapisano: »Kot del sistema zdravstvenega varstva je na voljo tudi turistom; pogosto je tudi storitvena dejavnost v turizmu, največkrat v zdraviliškem 
turizmu, in kot taka del ponudbe zdravstvenega in/ali zdraviliškega turizma.« (TURS, glej sliki 3, 4).

dejávnost -i ž delo, vezano na določeno področje

l...l

Razložene stalne zveze: /.../

zdravstvena $\sim$ ukrepi in aktivnosti, ki jih opravljajo zdravstveni delavci in sodelavci pri varovanju zdravja, preprečevanju, odkrivanju in zdravljenju bolnikov in poškodovancev na primarni (osnovna zdravstvena dejavnost, lekarniška dejavnost), sekundarni (specialistična, ambulantna in bolnišnična dejavnost) in terciarni ravni (dejavnosti klinik in inštitutov ter zdravstvenih zavodov);

l...l

Slika 3: Slovarski sestavek za termin zdravstvena dejavnost $\mathrm{v}$ Slovenskem medicinskem slovarju (Slo. med. slovar).

zdravstvena dejavnost samostalniška besedna zveza zdravstveni turizem, zdraviliški turizem / medicina

Dejavnost, ki zajema zdravljenje in varovanje zdravja na primarni (osnovna zdravstvena dejavnost, lekarniška dejavnost), sekundarni (specialistična, ambulantna in bolnišnična dejavnost) in terciarni ravni (dejavnosti klinik in inštitutov ter zdravstvenih zavodov). Kot del sistema zdravstvenega varstva je na voljo tudi turistom; pogosto je tudi storitvena dejavnost $\mathrm{v}$ turizmu, največkrat $\mathrm{v}$ zdraviliškem turizmu, in kot taka del ponudbe zdravstvenega in/ali zdraviliškega turizma.

○ zdraviliška zdravstvena dejavnost

- Kot predlog za izboljšanje obstoječega stanja bi za Terme Lendava kot podjetje, kjer je zdravstvena dejavnost prav tako ena glavnih dejavnosti, bilo zelo koristno zaposlene poslati na občasna izobraževanja in usposabljanja na temo strokovnosti in uspeřne komunikacije z gosti.

GL. dejavnost, zdraviliška dejavnost, zdravljenje, zdravstvena težava Angleški prevod: medical service, health service

Slika 4: Slovarski sestavek za termin zdravstvena dejavnost $\mathrm{v}$ Turističnem terminološkem slovarju (TURS).

Pri nekaterih terminih pa je vloga pojmovne vsebine v okviru turizma razvidna iz kvalifikatorjev in ponazarjalnega gradiva, saj se ti termini uporabljajo izključno $\mathrm{v}$ okviru navedenih vrst turizma ali turističnih (pod)področij in tega v definiciji ni potrebno dodatno izpostavljati (sliki 5, 6).

hídroterapíja -e ž zdravljenje z vodo (s kopelmi, vodnimi napravami)

Slika 5: Slovarski sestavek za termin hidroterapija v Slovenskem medicinskem slovarju (Slo. med. slovar). 
hidroterapija samostalnik

zdraviliški turizem / medicina

Vrsta zdravljenja bolezni in poškodb, pri katerem se uporablja kopeli in vodne naprave.

- hidroterapija s kromo- in aromaterapijo

- Ob poslopju sta bila velik bazen s 16 kabinami in vodno zdravilišce po

Priessnitzovi metodi (Vincenc Priessnitz, rojen 1799, je bil utemeljitelj moderne

hidroterapije) in z Riklijevimi parnimi posteljami.

GL. aromaterapija, elektroterapija, fizioterapija, talasoterapija, termoterapija

Angleški prevod: hydrotherapy

Slika 6: Slovarski sestavek za termin hidroterapija v Turističnem terminološkem slovarju (TURS).

\subsection{Primer večpodročnega turističnega termina z istim/sorodnim pomenom na vseh področjih}

Pogosto posamezni turistični termini prihajajo z dveh, treh ali, sicer redkeje, še več področij, pri čemer je pomen na vseh področjih isti oz. zelo soroden, ne glede na to, ali je en sam (npr. pri terminih kategorizacija s področij prava in gostinstva - slika 7, aromatični s področij kulinarika in medicina) ali je pomenov več (npr. večpomenski termin prvobitni s področij sociologija, psihologija in etnologija - slika 8). To pomeni, da gre za isti termin, ki se uporablja na več področjih oziroma hkrati pripada več področjem, vključno seveda s turističnim,. ki so ponavadi v določenem delu stvarnosti, ki jo termini opredeljujejo, medsebojno tesno povezana.

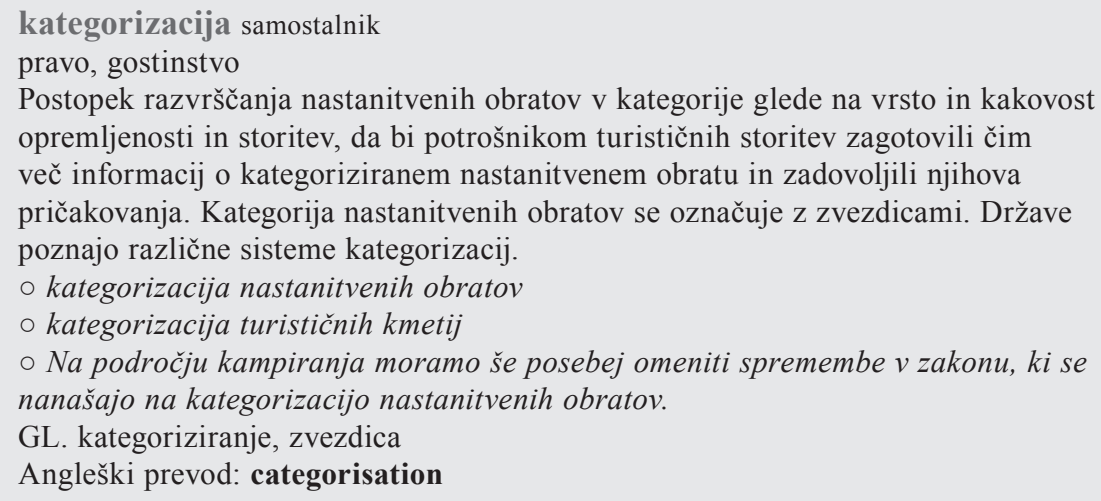

Slika 7: Slovarski sestavek za termin kategorizacija v Turističnem terminološkem slovarju (TURS). 
prvobitni pridevnik

ekoturizem / sociologija, psihologija, etnologija

1. Prvotni, osnovni.

2. Neponarejen, ki ni podlegel vplivom okolja.

o prvobitni cilj (1)

o prvobitni kmečki značaj (2)

- Regijski park - obsežno območje regijsko značilnih ekosistemov in krajine z večjimi deli prvobitne narave in območij naravnih vrednot, ki se prepletajo $z$ deli narave, kjer je človekov vpliv večji, a uravnotežen z naravo. (2)

$=(2)$ prvinski

Angleški prevod: primal $(1,2)$, original (2)

Slika 8: Slovarski sestavek za termin prvobitni v Turističnem terminološkem slovarju (TURS).

\subsection{Primer večpodročnega turističnega termina z različnimi pomeni na različnih področjih}

aranžma samostalnik

turistično posredništvo (1), cvetličarstvo (2), oblikovanje (2), umetnost (3), glasba

(3)

1. Vnaprej pripravljen turistični proizvod, ki ga organizator potovanja sestavi iz vsaj dveh delnih turističnih proizvodov za neznanega kupca. Najbolj pogosti turistični aranžmaji so počitnice, potovanja in izleti.

2. Na estetski način urejeno cvetje za dekoracijo.

3. Priredba nekega umetniškega dela (skladbe, dramskega dela ipd.) določeni zasedbi oziroma izvedbi.

- letalski aranžma (1)

- potovalni aranžma (1)

- Če stranka ne more plačati akontacije ob prijavi, se vseeno lahko sprejme rezervacija aranžmaja, vendar mora stranka plačati akontacijo v roku 24 ur. (1)

- Prinesemo naš pisni idejni načrt ter se dogovorimo o cvetličnih aranžmajih ter ostalem okrasju, kot so povezovalni trakovi in majhni aranžmaji za gumbnice. (2)

- Besedila pesmi je do sedaj pisala Anja, vendar smo v zadnjem času tudi ostali člani prijeli za svinčnike, aranžmaje delamo skupaj kot dobro utečena ekipa. (3)

= (1) paketni aranžma, (1) pavšalni proizvod, (1) turistični aranžma, (1) turistični paket, (3) priredba

GL. paket

Angleški prevod: tour package (1), flower arrangement (2), arrangement (3)

Slika 9: Slovarski sestavek za termin aranžma v Turističnem terminološkem slovarju (TURS).

Številni večpodročni termini so večpomenski in se v določenem pomenu uvrščajo na eno, v drugih pomenih pa na druga področja, kar je označeno s številko, pod katero je navedena definicija ustreznega pomena (npr. aranžma - turistično posredništvo (1), cvetličarstvo (2), oblikovanje (2), umetnost (3), glasba (3) - 
slika 9). Prav tako so oštevilčeni tudi vsi drugi elementi slovarskega sestavka (s številko v oklepaju), tako da je razvidna povezava z ustrezno definicijo. Vsi pomeni pa so seveda relevantni za turizem in se pogosto pojavljajo v turističnem diskurzu, zato so tudi evidentirani v TURS-u.

$\mathrm{V}$ teh primerih gre za neke vrste homonimne termine, tj. enakoizrazne termine, ki imajo na različnih področjih različne pomene. Ker pa med njimi navadno obstaja povezava glede na izvorno obliko termina, jih v TURS-u ne navajamo kot posebne iztočnice, pač pa kot različne pomene ene iztočnice (kot v primeru iztočnice aranžma na sliki 9).

\subsection{Primer večpodročnega termina z več pomeni s sorodnih področij}

Vsi elementi slovarskega sestavka, vključno z vrsto in področjem turizma, so označeni s številkami tudi v primeru, ko gre za termine s turističnih (pod)področij, ki so si sorodna oziroma se deli njihovih dejavnosti pokrivajo. Takšna področja so arhitektura, kiparstvo, kamnoseštvo in tesarstvo, s katerih prihaja termin spomenik s tremi različnimi pomeni, ki se uvrščajo v okvir enega ali več omenjenih področij (slika 10).

spomenik samostalnik

kulturni turizem / arhitektura (1, 2), kiparstvo $(1,2,3)$, kamnoseštvo (3), tesarstvo

(3)

1. Kulturna ali arhitekturna stvaritev, delo, objekt, ki ima zaradi značilne oblike ali redkosti poseben kulturni pomen, pogosto del ponudbe kulturnega turizma.

2. Kiparsko ali arhitekturno delo v spomin na določeno osebo, določen dogodek, pogosto del ponudbe kulturnega turizma.

3. Kamnoseško, kiparsko ali tesarsko delo na grobu v spomin pokojnika, lahko predstavlja del ponudbe kulturnega turizma.

o postaviti spomenik $(1,2,3)$

- kamniti spomeniki $(1,2,3)$

- Cerkev spada med najpomembnejše spomenike sakralne arhitekture na

Slovenskem. (1)

- Tesno pozidano naselje na razglednem slemenu griča med dolinama Branice in

Vipave je spomenik slovenske kulturne dediščine. (1)

- V Vipavi so Dragu Bajcu posvečena naslednja obeležja: spomenik (3) na pokopališču, delo Meštrovičevega učenca Franceta Goršeta, spomenik (2) pred Osnovno šolo Draga Bajca, delo Njegovana Nemca, in spominska plošča Dragu in Milanu Bajcu na njuni rojstni hiši.

= (1) kulturni spomenik, (3) nagrobni spomenik, (3) nagrobnik

GL. arhitekturni spomenik, naravni spomenik, zgodovinski spomenik

Angleški prevod: monument $(1,2)$, gravestone (3), tombstone (3)

Slika 10: Slovarski sestavek za termin spomenik v Turističnem terminološkem slovarju (TURS). 


\section{Sklep}

Označevanje turistične terminologije glede na vrsto in (pod)področje turizma vedno vključuje tudi določeno mero interpretativnosti, saj je kljub analizi konteksta rabe termina, ki jo omogoča korpusni pristop, od označevalca odvisno, ali in katero vrsto in področja turizma bo prepoznal kot relevantno za obravnavani termin. To je še posebej zahteven proces pri terminih, ki se uporabljajo $\mathrm{v}$ besedilih, za katera je značilna prisotnost in prepletanje več vrst in področij turizma. Kljub povedanemu pa se označevanje po vrsti in (pod)področju turizma zdi pomembno za kasnejše raziskave turizma, predvsem pa se na tak način izrazijo specifike slovenskega turizma (Mikolič 2013a: 29-30).

Pri prepoznavanju vrste in (pod)področja turizma ter s tem tudi pomena turističnega termina je torej pomembno sobesedilo, ki je v Turističnem terminološkem slovarju TURS razvidno iz ponazarjalnega gradiva. To je ključno bodisi pri prepoznavanju pojmovne vsebine pri terminih, ki so nastali s terminologizacijo splošne leksike, bodisi pri tistih z različnih turističnih (pod) področij, ki so obenem termini tudi drugih strokovnih področij. Slednji so na področju turizma zelo pogosti, kar se kaže tudi v številčnosti večpodročnih terminov, kjer se pomeni oziroma njihove pojmovne vsebine na različnih področjih različno prepletajo.

Nasploh se pri mladih, večdisciplinarnih in hitro razvijajočih se disciplinah, kjer se pojmovni sistem gradi hkrati z rabo v širši diskurzivni skupnosti, termini v veliki meri oblikujejo skozi rabo. Zato so zgledi dejanske rabe oz. korpusni pristop pomembni že pri gradnji slovarja, prav tako pa bo tudi uporabnik šele s pomočjo ponazarjalnega gradiva popolnoma razumel pomen in vlogo termina v okviru turistične dejavnosti. To je nedvomno pomembno tudi za konstituirajočo se turistično znanost, ki tako lahko na trdnejših temeljih, tj. na zgledih dejanske rabe, oblikuje svoj pojmovni aparat in vzpostavlja razmerja med različnimi strokami in vedami, ki sestavljajo to transdisciplinarno znanost. Hkrati pa so v ponazarjalnem gradivu razvidne specifike slovenskega turizma oziroma pojmovni svet, značilen za tiste turistične discipline, ki so tesno povezane s slovenskim turizmom.

\section{VIRI IN LITERATURA}

Amparo ALCINA (ur.), 2011: Teaching and learning terminology: new strategies and methods. Amsterdam, Philadelphia: J. Benjamin Publishing Company.

Tomi BREZOVEC, Aleksandra BREZOVEC, Tanja PLANINC, Žana ČIVRE, Polona ČERNIČ, Maša PUKLAVEC, 2011: 20 let turizma samostojne Slovenije: analiza slovenskega turizma od leta 1991 do 2010. Portorož: Fakulteta za turistične študije Turistica, 2011. http://issuu.com/slovenia/docs/20_let_turizma_final (dostop 17. 5. 2014).

Nevenka ČAVLEK, Boris VUKONIĆ (ur.), 2001: Rječnik turizma. Zagreb: Masmedia. 
Charles R. GOELDNER, J. R. Brent RICHIE, 2003: Tourism. Principles, Practices, Philosophies. Hoboken, New Jersey: John Wiley \& Sons, Inc.

Vojko GORJANC, 2010: Terminološko načrtovanje in upravljanje terminologije. Slavistična revija 58/1, 95-104.

Vojko GORJANC, Nataša LOGAR, 2007: Od splošnih do specializiranih korpusov načela gradnje glede na njihov namen. Razvoj slovenskega strokovnega jezika. Ur. Irena Orel. Ljubljana: Filozofska fakulteta, Oddelek za slovenistiko, Center za slovenščino kot drugi/tuji jezik. (Obdobja 24). 637-650.

Marjeta HUMAR (ur.), 2004: Terminologija v času globalizacije: zbornik prispevkov s simpozija Terminologija v času globalizacije. Ljubljana: Znanstvenoraziskovalni center SAZU, Založba ZRC.

Jafar JAFARI (ur.), 2013: Enyclopedia of Tourism. Routledge.

Marko JESENŠEK (ur.), 2007: Besedoslovne spremembe slovenskega jezika skozi čas in prostor. Maribor: Slavistično društvo Maribor. (Zora 49).

-- (ur.), 2011: Izzivi sodobnega slovenskega slovaropisja. Maribor: Mednarodna založba Oddelka za slovanske jezike in književnosti, Filozofska fakulteta. (Mednarodna knjižna zbirka Zora, 75).

Maja KONEČNIK RUZZIER, 2010: Trženje v turizmu. Ljubljana: Meritum.

Mateja KOŠIR, 2010: Slovenska filmska terminologija v korpusu filmskih kritik. Magistrsko delo. Nova Gorica: Univerza v Novi Gorici, Fakulteta za humanistiko. http:// www.ung.si/ library/magisterij/slovenisti/2Kosir.pdf (dostop 25. 4. 2014).

Philip R. KOTLER, John T BOWEN, James MAKENS, 2009: Marketing for Hospitality and Tourism. Pearson.

Nina LEDINEK, Mojca ŽAGAR KARER, Marjeta HUMAR (ur.), 2009: Terminologija in sodobna terminografija. Ljubljana: Založba ZRC, ZRC SAZU.

Lexicool.com - Lexicool.com Tourism Dictionaries. http://www.lexicool.com/online-dictionary.asp?FKW=tourism (dostop 25. 4. 2014).

Nataša LOGAR BERGINC, Špela VINTAR, 2008: Korpusni pristop k izdelavi terminoloških slovarjev: od besednih seznamov in konkordanc do samodejnega luščenja izrazja. Jezik in slovstvo 53/5, 3-17.

Nataša LOGAR, 2009: Korpusi v terminografiji: umik potrebe po introspektivni presoji. Terminologija in sodobna terminografija. Ur. Nina Ledinek, Mojca Žagar Karer, Marjeta Humar. Ljubljana: Založba ZRC, ZRC SAZU. 319-328.

Tanja MIHALIČ, 1998: Vodnik po ekonomiki turizma. Ljubljana: Ekonomska fakulteta.

Vesna MIKOLIČ, 2007: Tipologija turističnih besedil s poudarkom na turističnooglaševalskih besedilih. Jezik in slovstvo 52/3-4, 107-116.

- -, 2009: Specializirani jezikovni korpusi in funkcijska zvrstnost. Infrastruktura slovenščine in slovenistike. Ur. Marko Stabej. Ljubljana: Znanstvena založba Filozofske fakultete. (Obdobja 28). 257-263. 
- -, 2013: Področni govor in terminologizacija na primeru jezika turizma. Družbena funkcijskost jezika (vidiki, merila, opredelitve). Ur. Andreja Žele. Ljubljana: Znanstvena založba Filozofske fakultete. (Obdobja 32). 255-261.

- -, 2013a: Turistični terminološki slovar - predstavitev izhodišč in učinkov projekta ter opis slovarja TURS kot glavnega rezultata projekta. Elaborat. Koper: Univerza na Primorskem, Znanstveno-raziskovalno središče.

Vesna MIKOLIČ, Ana BEGUŠ, 2011: Meddisciplinarne pomenotvorne zmožnosti v procesih (de)terminologizacije turistične terminologije. Meddisciplinarnost v slovenistiki. Ur. Simona Kranjc. Ljubljana: Znanstvena založba Filozofske fakultete. (Obdobja 30). 313-319.

Vesna MIKOLIČ, Jernej VIČIČ, Jana VOLK, 2009: Namen in metode urejanja večjezičnega korpusa turističnih besedil (TURK). Jezikovni korpusi v medkulturni komunikaciji. Ur. Vesna Mikolič. Koper: Univerza na Primorskem, Znanstveno-raziskovalno središče, Založba Annales, Zgodovinsko društvo za južno Primorsko, 65-74.

Janez PLANINA, Tanja MIHALIČ, 2002: Ekonomika turizma. Ljubljana: Ekonomska fakulteta.

Slo.med.slovar - Slovenski medicinski slovar (2012). Ljubljana: Univerza v Ljubljani, Medicinska fakulteta. http://www.termania.net/slovarji/slovenski-medicinski-slovar/5511168/dejavnost?query=zdravstvena\%20dejavnost (dostop 26. 4. 2014).

Sonja Sibila LEBE idr., 2012: Leksikon turizma. Maribor: Multidisciplinarni raziskovalni institut.

Irena STRAMLJIČ BREZNIK, 2003: Besedotvorna tipologija novonastalega besedja s področja mobilne telefonije. Ljubljana: Slavistično društvo Slovenije. 105-118.

SSKJ - Slovar slovenskega knjižnega jezika. Ljubljana: Inštitut za slovenski jezika Frana Ramovša, ZRC SAZU. http://bos.zrc-sazu.si/sskj.html (dostop 26. 4. 2014).

Rita TEMMERMAN, 2000: Towards New Ways of Terminology Description: The Sociocognitive Approach. Amsterdam/Philadelphia: John Benjamins.

TURK - Vesna MIKOLIČ, Ana BEGUŠ, Jana VOLK, Davorin DUKIČ, Miha KODERMAN, 2009: Turistični korpus: večjezični korpus turističnih besedil. Koper: Univerza na Primorskem. http://jt.upr.si/turisticnikorpus (dostop 26. 4. 2014).

TURS - Vesna MIKOLIČ, Maja SMOTLAK, Klara ŠUMENJAK, Jana VOLK, Mojca KOMPARA, Martina RODELA, Elena ŠVERKO, Jernej VIČIČ, 2011: Turistični terminološki slovar. Kamnik: Amebis. http://www.termania.net/slovarji/78/turisticni-terminoloski-slovar (dostop 26. 4. 2014).

Špela VINTAR, 2008: Terminologija: terminološka veda in računalniško podprta terminografija. Ljubljana: Znanstvena založba Filozofske fakultete, Oddelek za prevajalstvo.

Sue Ellen WRIGHT, Gerhard BUDIN (ur.), 2001: Handbook of Terminology Management: 2 Volumes. Amsterdam, Philadelphia: J. Benjamin Publishing Company.

WTO, 2001 - Tezaver turizma in prostočasnih dejavnosti Svetovne turistične organizacije. Thesaurus on Tourism and Leisure Activities. World Tourism Organization (WTO), Secretariat of State for Tourism of France. 
Mojca ŽAGAR KARER, 2011: Terminologija med slovarjem in besedilom. Ljubljana: Založba ZRC, ZRC SAZU.

Andreja ŽELE, 2009: Enojezični slovarji - sledenje pomenskosti besed oz. kaj in kako pravi raba. Infrastruktura slovenščine in slovenistike. Ur. Marko Stabej. Ljubljana: Znanstvena založba Filozofske fakultete. (Obdobja 28). 457-461.

\section{GENERAL LEXIS AND MULTIDISCIPLINARY TERMINOLOGY IN TOURISM DISCOURSE}

The study shows the specific traits of tourism lexis, which is characterized by strong terminologization and de-terminologization processes, or rather, by the interaction of the general lexicon and interdisciplinary terminology within the field of tourism.

Furthermore, the study highlights multidisciplinarity and polysemy as characteristic phenomena stemming from the aforementioned linguistic processes. All of these traits are considered in the Dictionary of Tourism Terminology (TURS) as it is linked to a corpus of diverse authentic tourist texts (Tourism Corpus, TURK) and accessible through the Termania website that encourages professionals from different fields as well as tourism services users and providers to take part in the further development of tourism terminology. By considering the tourism discourse as a whole, i. e. the discourse of the entire tourism speech community in which common languages and various professional idioms intertwine, tourism studies can develop as a young, transdisciplinary field of study. Moreover, the lexical selection reflects the reality of Slovenian tourism, since the corpus method and term extraction show which fields, in regard to term frequency, are particularly relevant for Slovenian tourism.

The lexical entries in TURS provide information about the source field of a term through the indication of the type of tourism and the specific field indication, the definition of term, and illustrative examples. There are a vast number of multidisciplinary terms, where meanings and concepts intertwine differently in various fields. Thus, the dictionary differentiates between multidisciplinary terms with similar/related meanings across fields and multidisciplinary terms with different meanings in different or related fields. Terms that do not belong to any specific field are marked as general tourism terms and do not have a field indication.

When determining the type, the subfield of tourism and, therefore, the meaning of a tourism term, context, provided by the illustrative examples, is key. The examples are crucial for recognizing the concept of terms that emerged through the terminologization of general lexicon as well as those terms pertaining to different subfields of tourism and other specific fields at the same time. Generally speaking, the conceptual systems of young, multidisciplinary, quickly-expanding fields are developing simultaneously with the actual use within the broader discursive community, and the terms are therefore defined through use, as it is typical in the field of tourism. Examples of use, or rather, the corpus approach is essential for the construction of a dictionary, moreover, the illustrative material helps the user to fully comprehend the meaning and the role of a term within the context of tourism. 